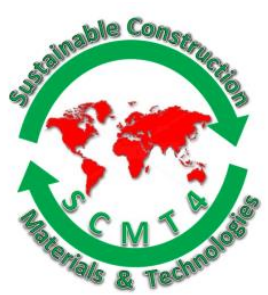

SCMT4

Las Vegas, USA, August 7-11, 2016

\title{
Influence of Cast and Cut Concrete Surfaces on Chloride Ingress Resistance of Concrete in Marine Splash Zone
}

\author{
K. De Weerdt ${ }^{* 1 a}$, M. Bernhardt ${ }^{2 a}$, M. Geiker ${ }^{1 b}$, O. Skjølsvold ${ }^{3}$ and K. O. Kjellsen ${ }^{2 b}$ \\ ${ }^{1}$ NTNU, Department of Structural Engineering, Richard Birkelands vei 1a, 7491 Trondheim, NORWAY. \\ ${ }^{*}$ Eamail: <klaartje.d.weerdt@ntnu.no>, ${ }^{1 b}$ Email: <mette.geiker@ntnu.no>. \\ ${ }^{2}$ Norcem, R\&D Department, NORWAY. ${ }^{2 a}$ Email: <markus.bernhardt@norcem.no〉, \\ ${ }^{2 b}$ Email: <knut.kjellsen@norcem.no>. \\ ${ }^{3}$ SINTEF Building and Infrastructure, Richard Birkelands vei 3, 7491 Trondheim, NORWAY. \\ ${ }^{3}$ Email: <ola.skjoldsvold@sintef.no>
}

\begin{abstract}
The aim of the study was to investigate the effect of the type of surface on the chloride ingress resistance of concrete.

Concrete cylinders with both cut and cast surfaces were exposed to sea water in the tidal zone at Østmarkneset in the Trondheim Fjord in Norway after approx. 1 months of curing. Chloride profiles were determined after 35, 200 days, 1, 2 and 5 years of exposure.

Three concretes with water-to-binder ratio 0.45 and with different cements were examined. One concrete was prepared with a coarse Portland cement, the second was prepared with a finely ground Portland cement, and in the third concrete $20 \%$ of the Portland cement was replaced by siliceous fly ash.
\end{abstract}

As expected, the samples with cast surfaces exhibited a distinct increase in the chloride content in the outer millimeters of the surface compared to deeper in the concrete. This relates to the higher cement paste content at the cast surface.

For the selected concretes, the cast surface lead at all tested ages to a slight increase in the resistance to chloride ingress compared to the cut surfaces.

\section{INTRODUCTION}

Chloride ingress resistance of concrete is relevant with respect to the resource efficiency and general sustainability as chloride induced reinforcement corrosion is one of the major deterioration mechanisms for reinforced concrete structures exposed to marine environment or de-icing salts.

This research is part of a larger research effort related to the service life of concrete structures. The outcome of this activity provides data from marine exposure between 1 month and 5 years. Results up to two years of exposure are reported in (Kjellsen and Skjølsvold 2003). 
One of the parameters investigated is the effect of surface type on the chloride ingress resistance of concrete: chloride ingress through cut and cast surfaces was compared.

At a cut surface, the aggregates are cut and the paste to aggregate ratio should be the same as in the bulk of the concrete. At a cast surface, a higher paste to aggregate ratio is expected either due to the wall effect when cast against a mold, or due to the finishing by troweling. The wall effect will cause fluctuations of the aggregated content, which gradually will level out. A minimum paste content will be found around a distance from the surface of half the maximum grain size.

The cement paste is the part of the concrete which interacts with the chlorides, aggregates can be considered inert. On the one hand, the paste provides a path into the concrete by its porosity. On the other hand, the paste can bind chlorides either by chemical binding in hydrates (e.g. Friedel's and Kuzel's salts) or by physical sorption (e.g. on C-S-H). An increase in the cement paste content at the surface will lead to a local increase in both the binding capacity and the porosity of the concrete.

In one of the commonly used accelerated chloride penetration tests in Europe, NT BUILD 443 (NT BUILD 443 1995), the removal of the paste enriched surface layer of the concrete is prescribed. In the case of cylinders cast in the laboratory, the cylinder should be cut in two and the cut surface is exposed to chloride ingress. In the case of cores drilled from existing structures, the outer $10 \mathrm{~mm}$ of concrete should be cut off. This is done in order to measure the chloride ingress resistance corresponding to the bulk concrete and to avoid any effect of the paste enriched surface layer. In the ASTM C1556 11a (ASTM C1556-11a 2011), which is the American version of the NT Build 443, the requirement of exposing a cut surface is however not included.

To the authors' knowledge, little research is reported on the possible differences between cast and cut on chloride resistance. In (Maage and Helland 2009) a tighter surface for cast compared to cut surfaces with respect to capillary adsorption is reported; and (Janz and Johannesson 1993) reported an improved chloride ingress resistance for cast surfaces compared to cut surfaces in laboratory conditions using $3 \%$ $\mathrm{NaCl}$ solution.

This paper addresses the potential impact of the surface type, i.e. cast vs cut, on the chloride ingress resistance of concrete in a marine splash zone. The research question is relevant both for performance testing and for the impact the surface finish on the service life of reinforced concrete structures.

\section{EXPERIMENTAL}

The chloride ingress in three concretes with different compositions (see table 1) was investigated. The concretes were produced at the SINTEF laboratory. All concretes had a water-to-binder ratio of 0.45 . The main difference between the concretes lies in the cements: C-PC contained a coarse Portland cement, FPC contained a fine Portland cement, and for the PC-FA a blended cement for which $20 \%$ of the Portland cement was replaced by siliceous fly ash. It should be noted that the clinker composition of the Portland cement used in all three concretes is the same.

For each concrete type, 12 cylinders with diameter $100 \mathrm{~mm}$ and length $200 \mathrm{~mm}$ were cast. After 23 days of curing in the laboratory submerged in water baths $\left(20^{\circ} \mathrm{C}\right)$, the cylinders were sawn in two, resulting in 24 cylinders with diameter $100 \mathrm{~mm}$ and length $100 \mathrm{~mm}$. The curved surfaces were coated with epoxy. This resulted in 24 cut surfaces and 24 cast surface to be exposed to sea water.

The cylinders were exposed in anchored wooden frames in the tidal zone at Østmarkneset at the Trondheim fjord, Norway, 28 days after casting. The wooden frames were open at all sides thereby 
allowing the sea water to run through them. The sea water composition at the Østmarkneset is similar to the composition of sea water from the Atlantic Ocean, and has a chloride concentration of $0.5 \mathrm{~mol} / \mathrm{L}$.

Table 1: Concrete recipes and fresh concrete properties

\begin{tabular}{|l|l|c|c|c|}
\hline \multicolumn{1}{|c|}{ Concrete recipes [in kg/m ${ }^{3}$ ] } & C-PC & F-PC & PC-FA \\
\hline \multirow{2}{*}{ Cement $2.5 \mathrm{R}^{*}$} & 369 & 369 & \\
\cline { 2 - 5 } & \multicolumn{1}{|c|}{ CEM II A-V 42.5 R* } & & & 369 \\
\hline \multirow{2}{*}{ Aggregate } & $0-8 \mathrm{~mm}$ & 1078 & 1082 & 1083 \\
\cline { 2 - 5 } & $2-8 \mathrm{~mm}$ & 717 & 720 & 720 \\
\hline \multirow{2}{*}{ Water } & 165 & 167 & 166 \\
\hline Admixtures & 5 & 6.3 & 4.8 \\
\hline Density & 2330 & 2340 & 2340 \\
\hline Blaine specific fineness of cement [m²/kg] & 350 & 520 & 430 \\
\hline Water-to-binder ratio [-] & 0.45 & 0.45 & 0.45 \\
\hline Slump [mm] & 100 & 125 & 150 \\
\hline Air content [\%] & 5.1 & 4.8 & 3.7 \\
\hline
\end{tabular}

* According to EN197

Cores were retrieved after 35 days, 200 days, 1 year, 2 years and 5 years of exposure. The cores were profile ground from the exposed concrete surfaces with intervals of 1.0 to $4.0 \mathrm{~mm}$. The chloride content was determined using the spectrophotometric analyses method (Basett et al. 1978), giving the total chloride content as a percentage of the dry concrete mass. Two parallel cores were examined for the exposure ages 35 days, 200 days, and 1 year. Three parallel cores were analyzed for 2 years and 5 years of exposure.

For the chloride profiles obtained after 5 years of exposure, the apparent diffusion coefficient, $D_{\text {app }}$, and the surface concentration, $C_{\mathrm{s}}$, were determined by fitting the data to equation (1) which is the solution of Fick's $2^{\text {nd }}$ law of diffusion according to (fib 2006).

$C(x, t)=C_{s}-\left(C_{s}-C_{i}\right) \cdot\left[\operatorname{erf} \frac{x}{2 \cdot \sqrt{D_{a p p} \cdot t}}\right]$

Where $x$ is the depth expressed in $\mathrm{m}$, and $t$ the exposure time in $\mathrm{s}$. The authors assumed an initial chloride concentration, $C_{\mathrm{i}}$, of $0.0001 \%$. It should be noted that the data points in the outer $8 \mathrm{~mm}$ were not included in the calculation.

For the sake of simplicity the figures show average values and standard deviations (the difference if only two measured values) calculated based on the results obtained on the parallel samples. In the figures the exposure ages are abbreviated by "d" for days and "y" for years. 


\section{RESULTS}

Figure 1 shows the chloride profiles for the three investigated concrete compositions after 35 days, 200 days, and 1, 2 and 5 years of exposure in the tidal zone of the Trondheim fjord. Figure 2 shows the first $10 \mathrm{~mm}$ of the chloride profiles in order to observe the difference between the chloride content in the outermost section and the following sections. Figure 3 shows the calculated apparent diffusion coefficient, $D_{\mathrm{app}}$, and the surface concentration, $C_{\mathrm{s}}$, for the different concrete compositions after 5 years of exposure in the tidal zone. The calculated values should only be used as approximates because equation (1) does not fit the profiles well, which amongst others can be explained by the exposure in the tidal zone.

\section{DISCUSSION}

\section{Chloride profiles}

From figure 1 it can be seen that during the first year of exposure, there is no considerable difference in the chloride ingress depth between the investigated concretes. However, after 5 years exposure the PC-FA concrete shows lower ingress depths compared to the C-PC and F-PC concrete, thereby indicating a superior long-term resistance of PC-FA to chloride ingress compared to C-PC and F-PC. This is also demonstrated by the considerably lower apparent diffusion coefficient, $D_{\text {app }}$, for PC-FA after 5 years of exposure compared to the other concretes, as shown in figure 3.

The effect of the surface type, i.e. cast or cut, can be observed in figure1 by comparing the profiles with solid (cast) and dotted (cut) lines of the same color. Except for the outermost section, the profiles from the cut surfaces (dotted lines) generally show higher chloride contents compared to the cast surfaces (solid lines), thereby indicating a reduction in chloride penetration resistance for cut surfaces compared to the cast surfaces. The fitted parameters after 5 years of exposure, shown in figure 3 indicate a slightly lower apparent diffusion coefficient, $D_{\text {app }}$, and surface concentration, $C_{\mathrm{s}}$, for cast surfaces compared cut surfaces. Similar trends were observed after 1 and 2 years of exposure. However, the differences in the parameters depending on the surface finish are not significant when considering the standard deviation calculated from three parallel samples.

\section{Outer $10 \mathrm{~mm}$ of the chloride profiles}

When looking closer at the first $10 \mathrm{~mm}$ of the chloride profiles (see figure 2), all concretes show a distinct higher chloride content in the outermost section for the cast surfaces (solid lines) compared to the chloride content in the sections deeper into the concrete. This can be ascribed to the relatively higher paste content in the outermost section of the cast surfaces.

In the case of cut surfaces (dotted lines) high chloride contents are not observed near the surface. For the Portland cement concretes (C-PC and F-PC) there is a more gradual decrease of the chloride content when going inwards from the cut surface. For the fly ash containing concrete (PC-FA) with cut surface (dotted lines) the chloride content in the outermost section is even slightly lower than the following sections for exposure ages from 200 days and longer. This has been ascribed by De Weerdt et al. (De Weerdt et al. 2015, De Weerdt et al. 2016) to leaching of the concrete in the outermost section. The results indicate that the PC-FA is more prone to leaching than the Portland cement concretes.

Figure 4 shows the chloride content as mass $\%$ of dry concrete in the outer $0-1 \mathrm{~mm}$ section of the concrete for the different investigated concretes. For all concretes, the chloride content in the outermost section tends to increase with exposure time. The increase is most pronounced for the PC-FA concrete with cast surface. As mentioned above, the chloride content in the $0-1 \mathrm{~mm}$ section is higher for the cast surface (solid line) compared to the cut surface (dotted line); see figure 4. 

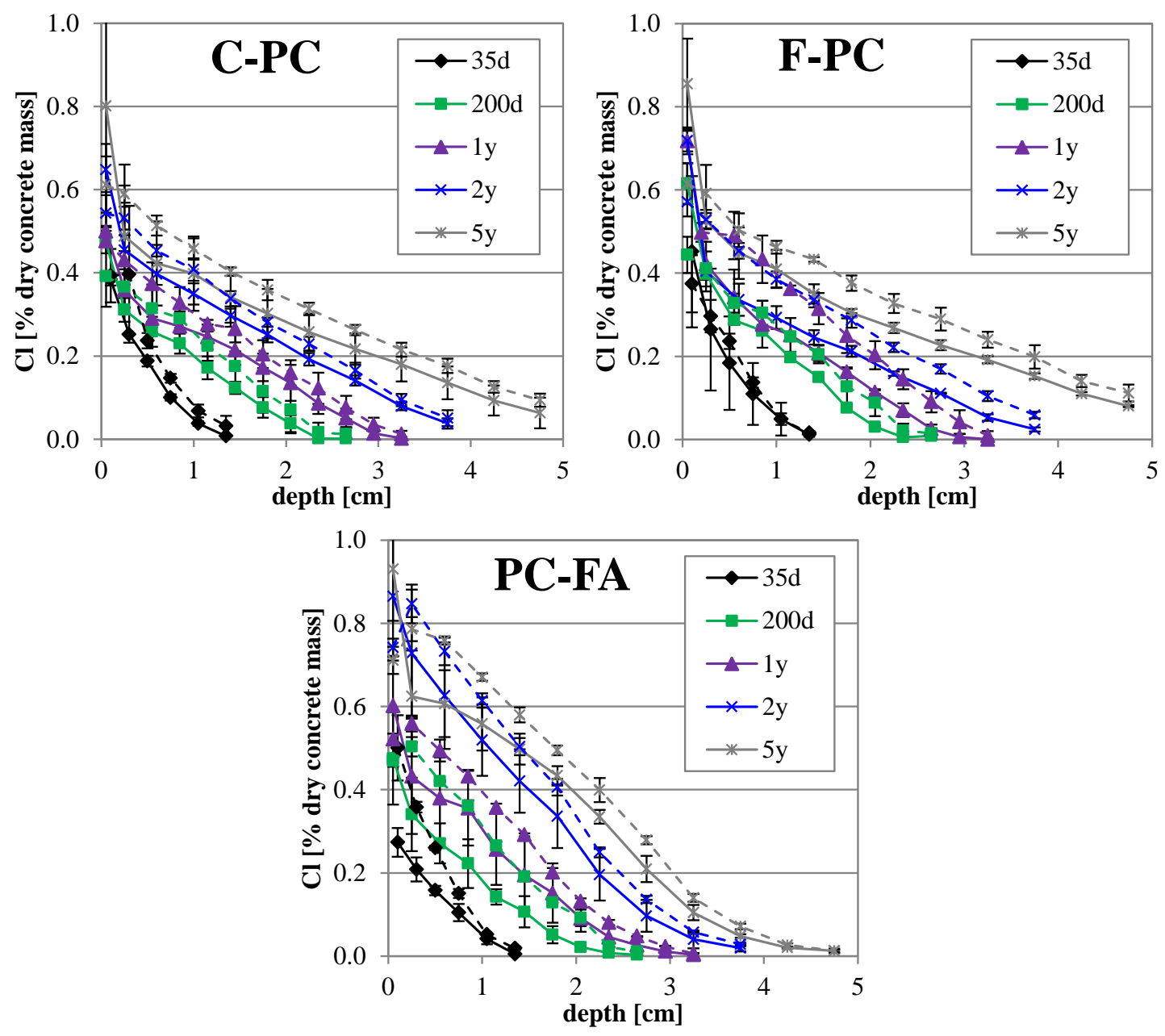

Figure 1. Chloride profiles of the three different concrete compositions C-PC, F-PC and PC-FA for exposure times in the tidal zone for 35 days, 200 days, and 1, 2 and 5 years. The doted lines correspond to the cut surfaces and the solid lines to the cast surfaces. The chloride concentration is given as mass \% of dry concrete. The standard deviations indicated in the graphs are calculated based on 2 or 3 parallel samples.

\section{Chloride ingress depth}

Figure 5 shows the depth at which the chloride content of 0.1 mass $\%$ of the dry concrete is reached. Comparing ingress depths at which $0.1 \%$ chloride is reached is relevant with respect to the risk of reinforcement corrosion.

For all investigated concretes and all tested exposure times, the samples with cast surfaces appear to have a slightly superior chloride ingress resistance compared to the samples with cut surfaces.

The graphs in figure 5 also demonstrate that the superior chloride ingress resistance of the PC-FA concrete after 5 years of exposure. At shorter exposure ages the difference between the concretes is limited. 

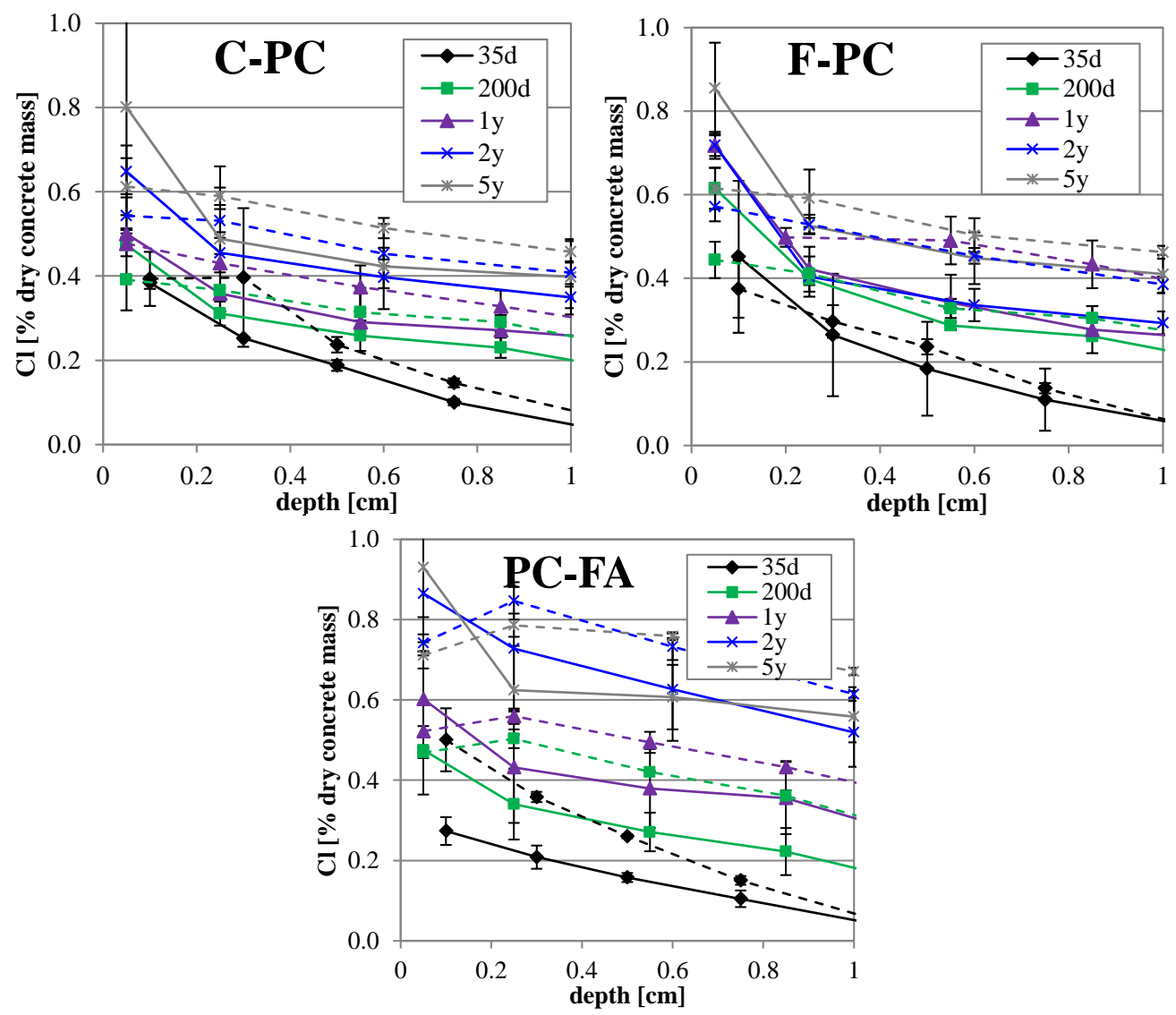

Figure 2. Chloride profiles of the three different concrete compositions C-PC, F-PC and PC-FA for exposure times in the tidal zone for 35 days, 200 days, and 1, 2 and 5 years. The doted lines correspond to the cut surfaces and the solid lines to the cast surfaces. The chloride concentration is given as mass $\%$ of dry concrete. The standard deviations indicated in the graphs are calculated based on 2 or 3 parallel samples. ZOOMED INTO FIRST $10 \mathrm{~mm}$ of Figure 1.
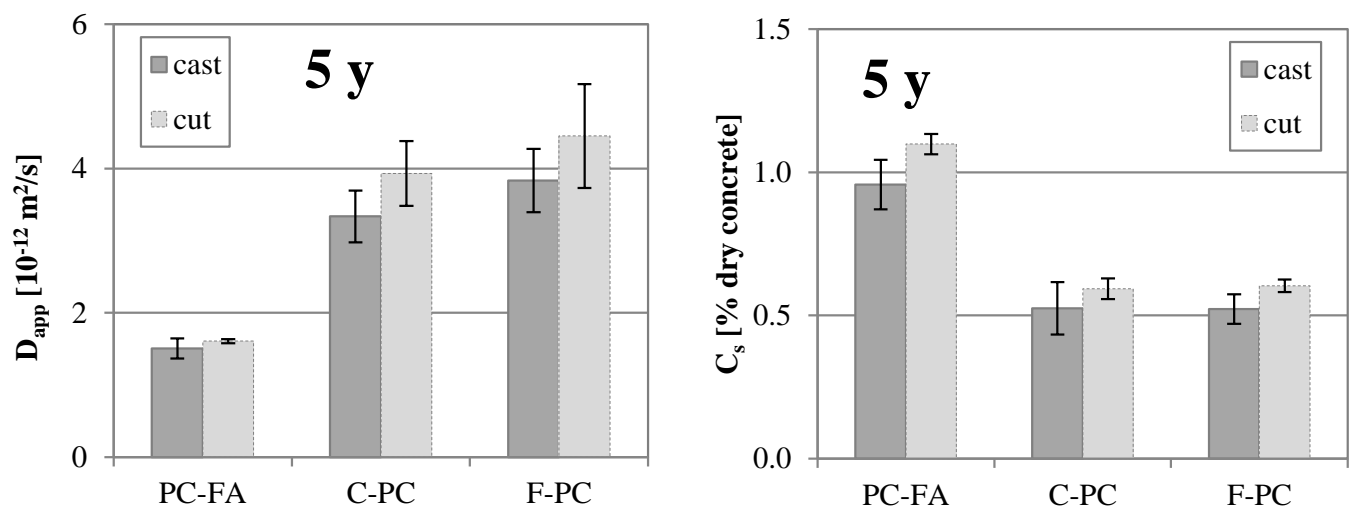

Figure 3. The calculated apparent diffusion coefficient, $D_{\text {app}}$, and the surface concentration, $C_{s}$, for three different concrete compositions 5 years of exposure in the tidal zone. The standard deviations indicated in the graphs are calculated based on 3 parallel samples. 

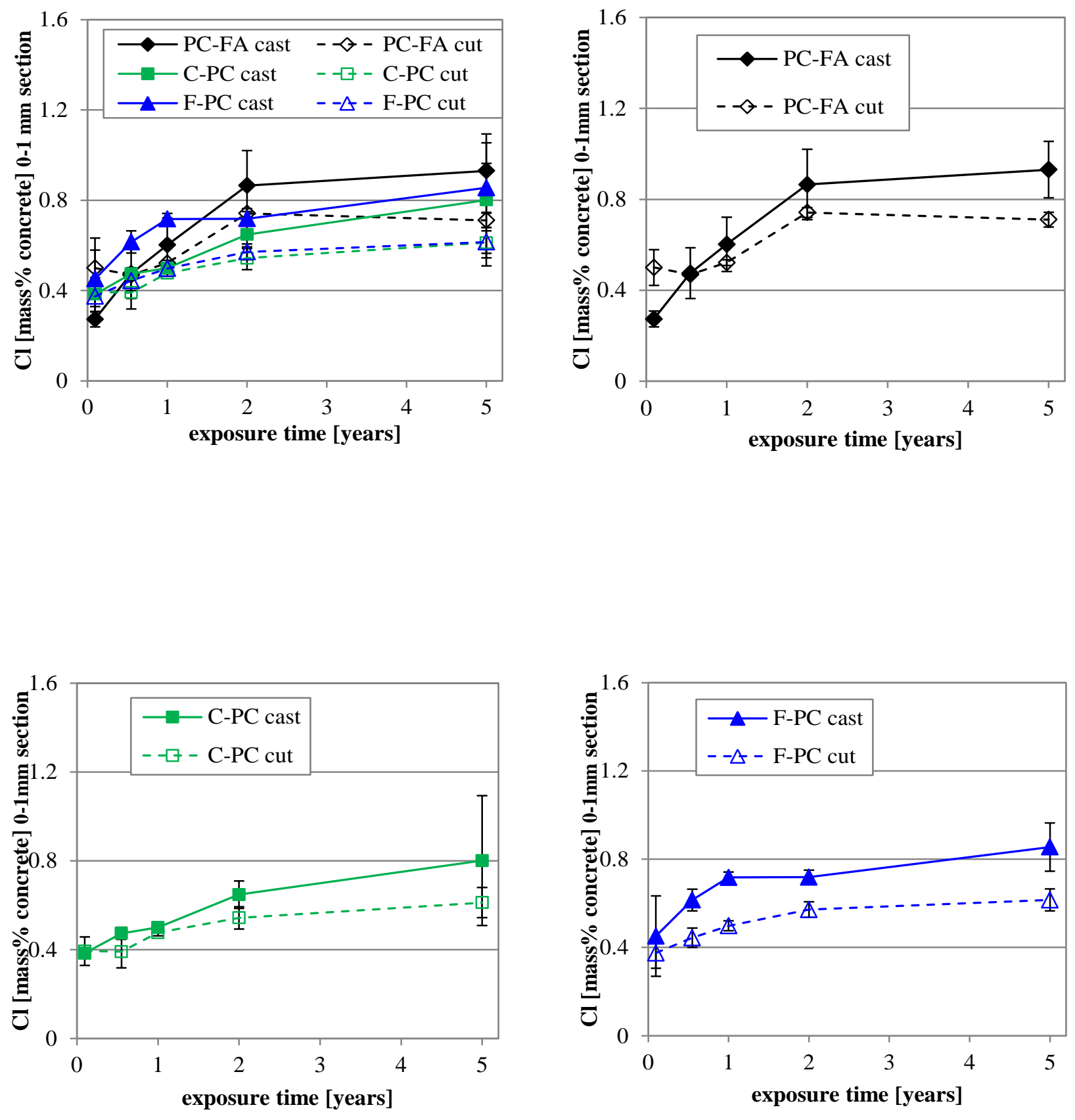

Figure 4. The chloride content as mass \% of dry concrete in the outer 0-1 mm section after exposure in the tidal zone for 35 days, 200 days, and 1, 2 and 5 years. The doted lines correspond to the cut surfaces and the solid lines to the cast surfaces. The standard deviations indicated in the graphs are calculated based on 2 or 3 parallel samples. Note: At 35 days of exposure the outermost section was $0-2 \mathrm{~mm}$ instead of $0-1 \mathrm{~mm}$. 

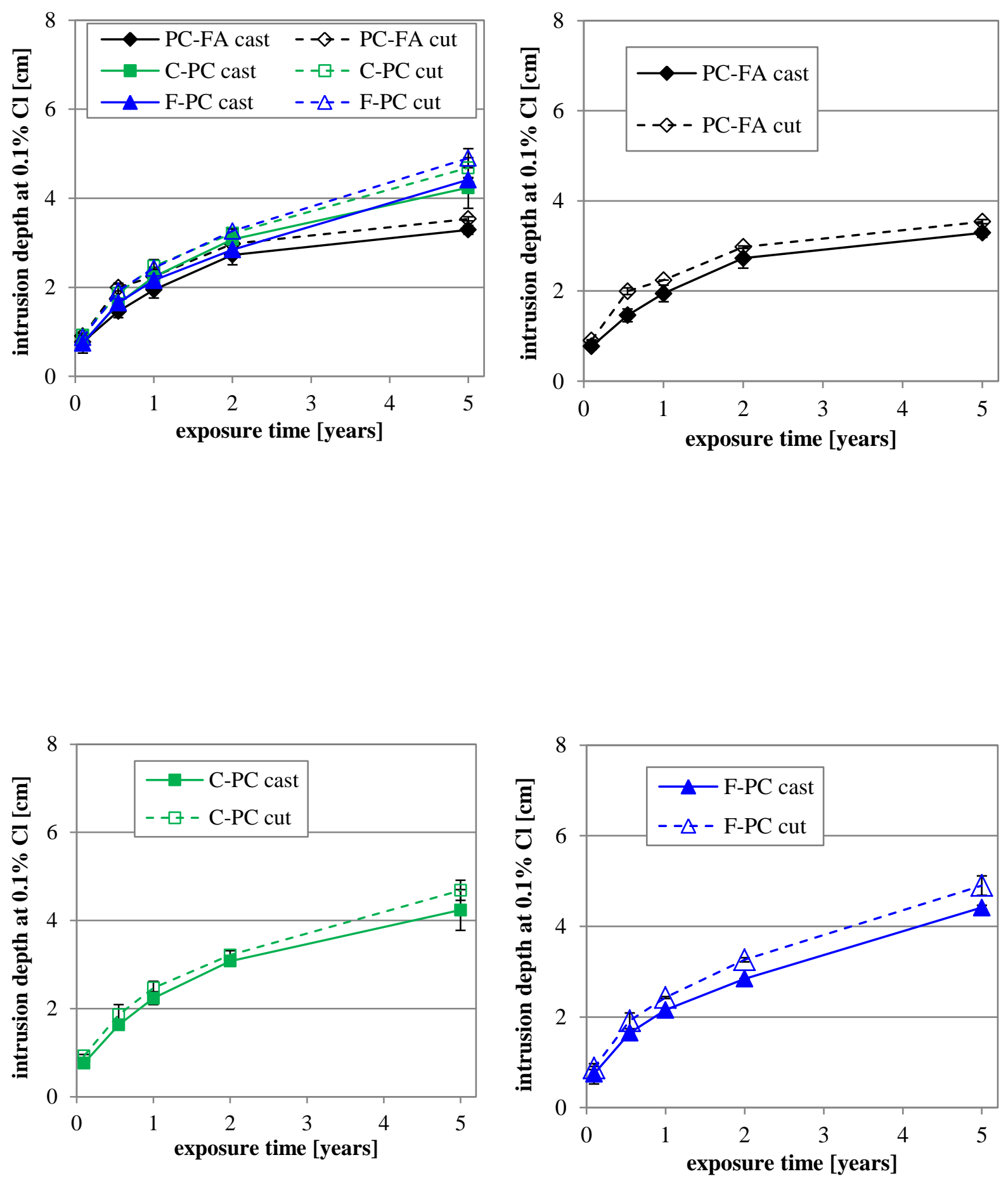

Figure 5. The intrusion depth in [cm] at which a level of $0.1 \%$ of chloride is reached after exposure in the tidal zone for 35 days, 200 days, and 1, 2 and 5 years. The doted lines correspond to the cut surfaces and the solid lines to the cast surfaces. The standard deviations indicated in the graphs are calculated based on 2 or 3 parallel samples. 


\section{CONCLUSION}

The aim of the study was to investigate the effect of the type of surface, i.e. cast or cut surfaces, on the chloride ingress resistance of concrete.

Concrete cylinders with both cut and cast surfaces were exposed to sea water in the tidal zone at Østmarkneset in the Trondheim Fjord in Norway after 1 month of curing. Chloride profiles were determined after 35, 200 days, 1, 2 and 5 years of exposure.

Three concretes made from different cements were examined (water-to-binder ratio 0.45 ). One of the concretes was prepared with a coarse Portland cement, the other concrete with a fine ground Portland cement, and in the third concrete $20 \%$ of the Portland cement was replaced by siliceous fly ash. The following conclusions could be drawn:

- Cast surfaces resulted in a slightly improved chloride ingress resistance of all three concretes compared to cut surfaces.

- Cast surface resulted in notably higher chloride contents in the outermost section compared to the concretes with a cut surface. This is attributed to a relatively higher paste content at the cast surfaces.

- A comparable chloride ingress resistance was observed for the concretes produced with fine or coarse Portland cement.

- The concrete prepared with the Portland - fly ash cement showed superior chloride ingress resistance compared the Portland cement concretes after 5 years of exposure.

\section{ACKNOWLEDGEMENT}

This research was initiated in the R\&D project 'Resource Efficient Quality Concrete' (Ressursvennlig Kvalitetsbetong, 1996-1998) with Norcem AS as project owner. The research was continued in the project 'Concrete Structures Service Life' (Betongkonstruksjoners Livsløp, 1999-2001) headed by the Norwegian Public Road Administration. Both projects were supported financially by the Norwegian Research Council. The experimental set-up was designed by Mrs. G. Lundevall and Dr. T.F. Rønning at Norcem AS.

\section{REFERENCES}

ASTM C1556-11a (2011). "Standard test method for determining the apparent chloride diffusion coefficient of cementitious mixtures by bulk diffusion". A. International. West Conshohocken, PA, ASTM Internatinal.

Basett, J., R. C. Denney, G. H. Jeffery and J. Mendham (1978). Vogel's textbook of quatitative inorganic analysis - Fourth edition. London, Longman Group Limited.

De Weerdt, K., M. R. Geiker and D. Orsakova (2015). "Investigation of concrete from Solsvik field station - 4 concrete cores investigated after 16 years of submerged exposure". Statens vegvesens rapporter. Oslo, Norwegian Public Roads Administration.

De Weerdt, K., D. Orsáková, C. Müller, C. K. Larsen, B. Pedersen and M. R. Geiker (2016). "Towards the understanding of chloride profiles in marine exposed concrete, impact of leaching and moisture content." Construction and Building Materials Under review.

fib (2006). "Model Code for Service Life Design - Bulletin 34", Fédération International du Béton: 116. 
Janz, J. and B. Johannesson (1993). "A Study of Chloride Penetration into Concrete (in Swedish)". Lund, Sweden, Division of Building Technology, Lund University of Technology.

Kjellsen, K. O. and O. Skjølsvold (2003). "Kloridinntrenging i ressursvennlig kvalitetsbetong DP1 A2 Rapport nr 4 (in Norwegian)". Betongkonstrukjsoners livsløp. Oslo, Norway, Norwegian Public Road Administration.

Maage, M. and S. Helland (2009). "Shore Approach. 26 years performance of high quality concrete in a marine environment". COIN Project Report. Trondheim, Norway, SINTEF. 14.

NT BUILD 443 (1995). "Concrete, Hardened: Accelerated chloride penetration". Nordtest. Espoo. 